\title{
Computational Analyses of Pressurization in Cryogenic Tanks
}

Vineet Ahuja, Ashvin Hosangadi, Stephen Mattick and Chun P. Lee

Combustion Research and Flow Technology, Inc. (CRAFT Tech)

6210 Keller's Church Road, Pipersville, PA 18947

Phone: 215-766-1520 / Fax: 215-766-1524

and

Robert E. Field and Harry Ryan

NASA Stennis Space Center, MS 39529, USA

\author{
44rd AIAAIASME/SAEIASEE \\ Joint Propulsion Conference \& Exhibit \\ 21-23 July 2008, Hartford, CT
}




\section{Motivation}

Analyses of Tank Pressurization Systems

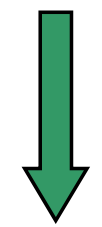

Exploration Missions

- Heat Transfer from different sources such as solar radiation contributing to solar radiation

-Large amplitude Sloshing during vehicle maneuvers, engine burn, orbital insertion

-Thermal stratification in variable gravity environments

-Control systems condition the tank during orbital engine start-up

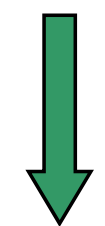

Ground Test Operations

-Ultra-high pressure source of gas at ambient temperature used to pressurize tanks

-Turbulent Mixing in Tank

-Tank comprises of entire fluid dynamic spectrum from compressed cryogenic liquid, supercritical, superheated compressible

-Scenarios include cryo-collapse in the tank 


\section{REGIMES OF TANK PROBLEMS AND APPROPRIATE MODELS(Exploration)}

Lumped Parameter

Thermodynamic Models Simplified CFD Models

Simplified CFD Models with more elaborate heat transfer

Multi-Phase CFD models Interface tracking I capturing techniques Surface Tension

Multi-Phase CFD models Mesh motion/grid adaption

Elaborate Multi-Phase CED models with soy-Phase etc.

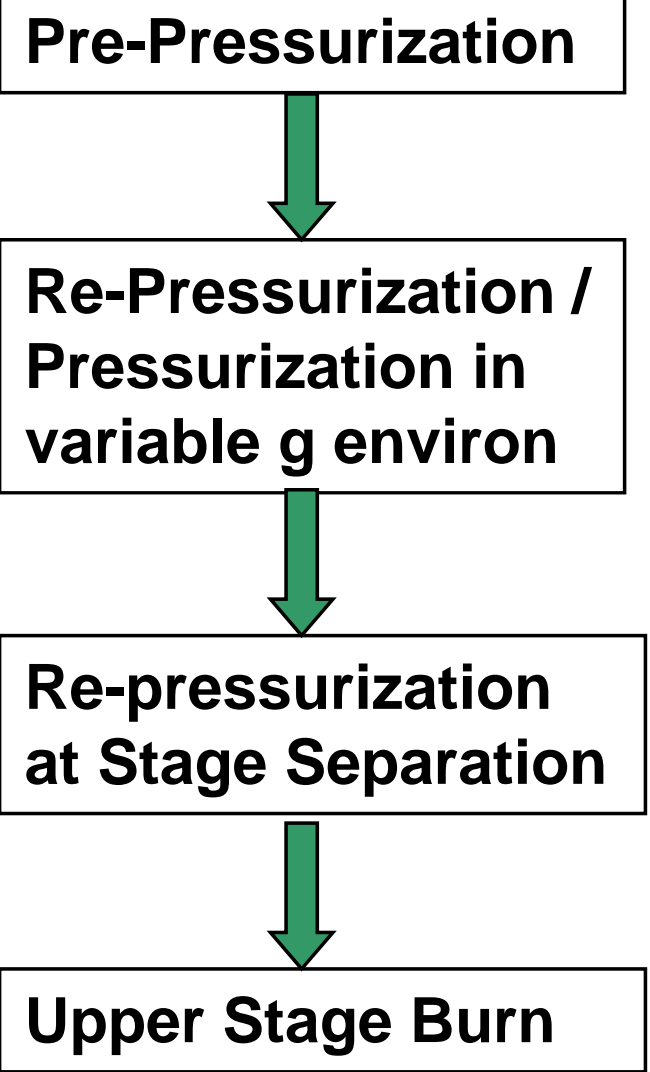

Self-Pressurization Thermal/Pressure Control Systems
Free/Forced Convection Heat Transfer

$+$

Low Amplitude Slosh $+$

High Amplitude Slosh $+$

Flow dynamics associated with drain 


\section{REGIMES OF TANK PROBLEMS AND APPROPRIATE MODELS(Ground)}

Thermodynamic Heat Transfer Models

System Level Codes such as RPTA

Multi-Phase CFD Models with Real Fluid Effects

Multi-Phase CFD Models with Interface Tracking
Tank Chill Down

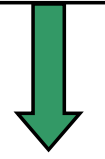

Tank Pressurization

Runtime Propellant Draw Down \& Purge
Heat Transfer

$+$

Mixing, Phase Change, Existence of Subcritical/Supercritical States

$+$

Drain related flow dynamics 


\section{Generalized Multi-Phase Computational Framework}

- Computational Framework For Mixture Set of Equations

- Gas-Liquid Interface Captured as part of Solution Procedure

- Acoustics of Two-Phase Regime Accurately Captured

- Phase Change Problems such as cryogenic cavitation modeled by Finite Rate Kinetics

- Tank Pressurization Problems require a broader operating envelope $(P, T)$ from classical cryogenic cavitation problems

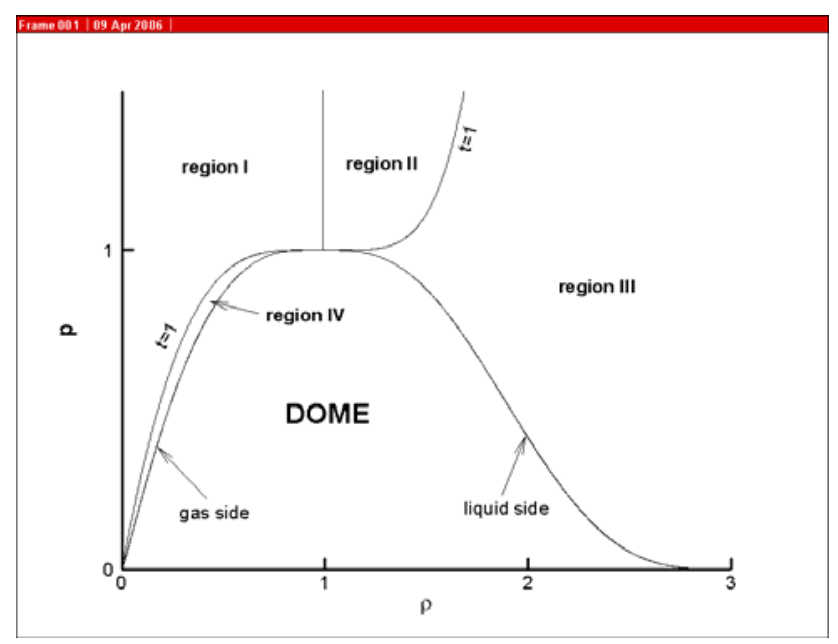

- Properties related to Sub-critical and Supercritical States are obtained directly from Specialized Equations of State

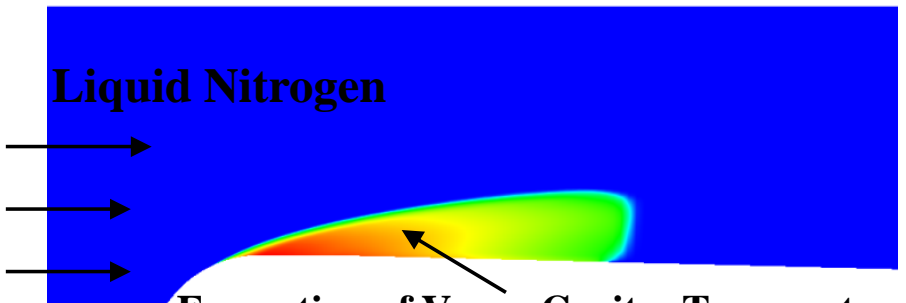

Formation of Vapor Cavity; Temperature depresses as a consequence of cryogenic cavitation

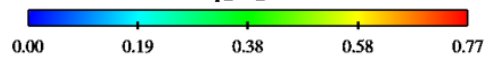

Cryogenic Cavitation
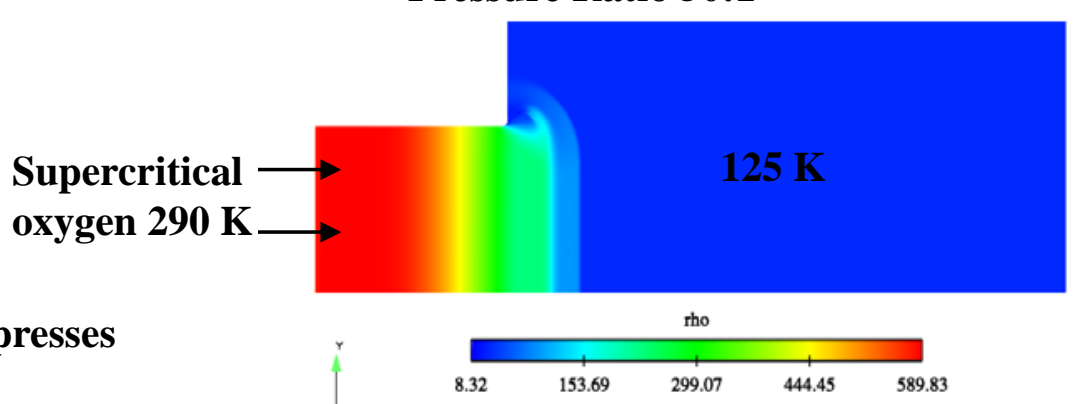

Supercritical Flow in Chamber with Sub-critical conditions 


\section{GENERALIZED PRECONDITIONING FORMULATION}

- Generalized Real Fluid, MultiComponent Formulation

- Allows for user specified mixture of gases and liquid

- Phase change driven by vapor pressure of liquid phase

\section{- Versatile Formulation}

- Pressure and Temperature are solved for directly allowing "stiff" components to be modeled

- Flux formulation retained in generalized thermodynamic form

$$
\left(\rho_{\mathrm{P}}, \rho_{\mathrm{T}}, \mathrm{H}_{\mathrm{p}}, \mathrm{H}_{\mathrm{t}}\right)
$$
- Thermodynamic properties can be $\overline{\text { specified as user input either in }}=$ analytical form or tabular look-up

- Framework has been used to model wide range of problems ranging from transcritical injectors, lowspeed tank problems, to cavitating turbopumps

$$
\begin{array}{|c|}
\Gamma \frac{\partial Q_{v}}{\partial t}+\frac{\partial E}{\partial x}=S+D_{v} ; \\
\Gamma=\frac{\partial Q}{\partial Q_{v}} ; \quad A=\Gamma^{-1} \frac{\partial E}{\partial Q_{v}}
\end{array}
$$

$$
Q=\left[\begin{array}{l}
\rho \\
\rho u \\
\rho e \\
\rho Y_{i}
\end{array}\right] ; Q_{v}=\left[\begin{array}{c}
p \\
u \\
T \\
Y_{i}
\end{array}\right]
$$

$$
\left.\begin{array}{cccc}
\rho_{p} & 0 & \rho_{T} & \rho_{\mathrm{y}_{\mathrm{i}}} \\
u \rho_{p} & \rho & u \rho_{T} & u \rho_{\mathrm{y}_{\mathrm{i}}} \\
H \rho_{p}-\left(1-\rho h_{p}\right) & \rho u & H \rho_{T}-\left(1-\rho h_{T}\right) H \rho_{\mathrm{y}_{\mathrm{i}}}+\rho h_{y_{i}} \\
Y_{i} \rho_{P} & 0 & Y_{i} \rho_{T} & Y_{i} \rho_{Y_{i}}+\rho \delta_{i j}
\end{array}\right]
$$




\section{SOLUTION PROCEDURE}

- System cast in

"Compressible" Framework

- Eigensystem Characteristics Similar for All Systems

- "Effective" Speed of Sound is defined for multi-fluid mixtures

- Exploit Compressible System Techniques to Efficiently Solve equations

- Use Approximate Riemann Solver of Roe

- Can Use Any Characteristics Based Flux /Flux-difference Splitting Method

- Preconditioning Technique to Over Come Numerical

\section{Stiffness}

- $\Gamma$ Matrix Is Modified Using Scaling Parameter $\beta$

- Reduces Eigen-values to More Matched Form

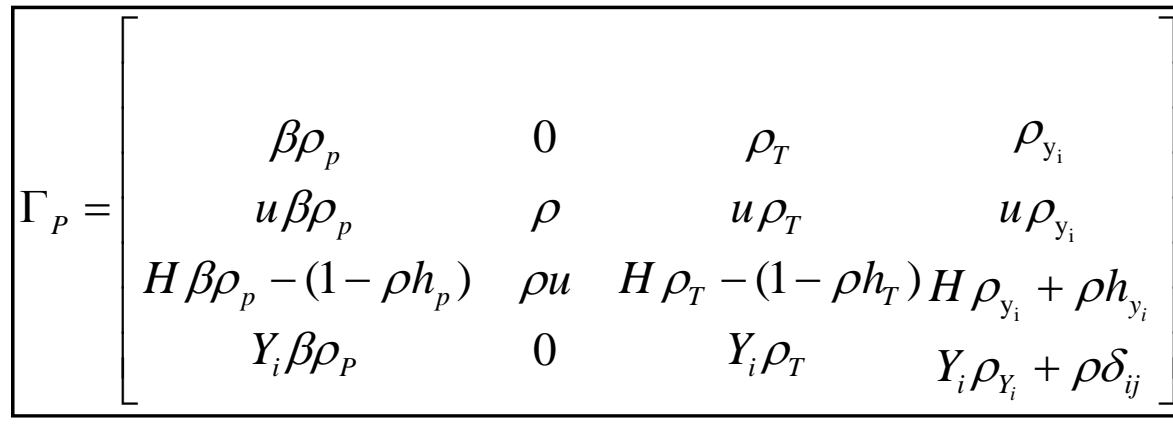

\section{Modified $\Gamma$ Matrix}

$$
\begin{aligned}
& F_{m}=\frac{1}{2}\left[F\left(Q_{\psi, m}\right)+F\left(Q_{v, m}^{+}\right)\right]-\frac{1}{2}\left[\Gamma_{P}\left(\Gamma_{P}^{-1} A\right)\left(Q_{\psi, m}^{+}-Q_{\psi, m}\right)\right] \\
& F_{m}=\frac{1}{2}\left[F\left(Q_{u, m}\right)+F\left(Q_{\psi, m}^{+}\right)\right]-\frac{1}{2}\left[\Gamma_{P}\left(\tilde{R}_{P} \tilde{\Lambda}_{P} \tilde{L}_{P}\right)\left(Q_{u, m}^{+}-Q_{\psi, m}\right)\right]
\end{aligned}
$$

\section{Modified Flux}

$$
\begin{gathered}
\Lambda_{P}=\left(\frac{u}{2}\left(1+\frac{1}{\beta}\right)+c_{m}^{\prime}, \frac{u}{2}\left(1+\frac{1}{\beta}\right)-c_{m}^{\prime}, u, u, u, u, u\right) \\
c_{m}^{\prime}=\frac{1}{2} \sqrt{u^{2}\left(1-\frac{1}{\beta}\right)^{2}+4 \frac{c_{m}^{2}}{\beta}} ; \quad \beta=\left(c_{m}^{2} / u^{2}\right)
\end{gathered}
$$




\section{EOS OPTIONS FOR GAS/LIQUID MIXTURES}

Mixture Density is defined as

$$
\begin{array}{cc}
\rho_{m}=\sum_{i=1}^{n s} \rho_{i} \phi_{i} \quad \text { where } & \phi_{i}=\frac{y_{i} \rho_{m}}{\rho_{i}} \\
\therefore \rho_{m}=\frac{1}{\sum_{i=1}^{n s}\left(y_{i} / \rho_{i}\right)} & \begin{array}{c}
\rho_{i} \text { obtained form EOS for each } \\
\text { fluid independently }
\end{array} \\
h_{m}=\sum_{i=1}^{N S} \rho_{i} \phi_{i} h_{i}=\sum_{i=1}^{N S} y_{i} h_{i} & \begin{array}{c}
h_{i} \text { obtained form EOS for each } \\
\text { fluid independently }
\end{array}
\end{array}
$$

Note that the EOS can be (a) ideal gas equation (b) curve fits (c) cubic or higher order polynomial equations of state(SRK/BWR) (d) any specified equation of state(HBMS) 


\section{GAS-LIQUID EOS ROUTINES}

- Mixtures of Simple Gases and Liquids

- Utilized for operating temperatures far from Critical Point

- Gases Modeled with Ideal Gas Equation

- Liquids Modeled with Linearly Varying Properties

- Properties of Cryogenic Liquids show Strong Dependence on Temperature

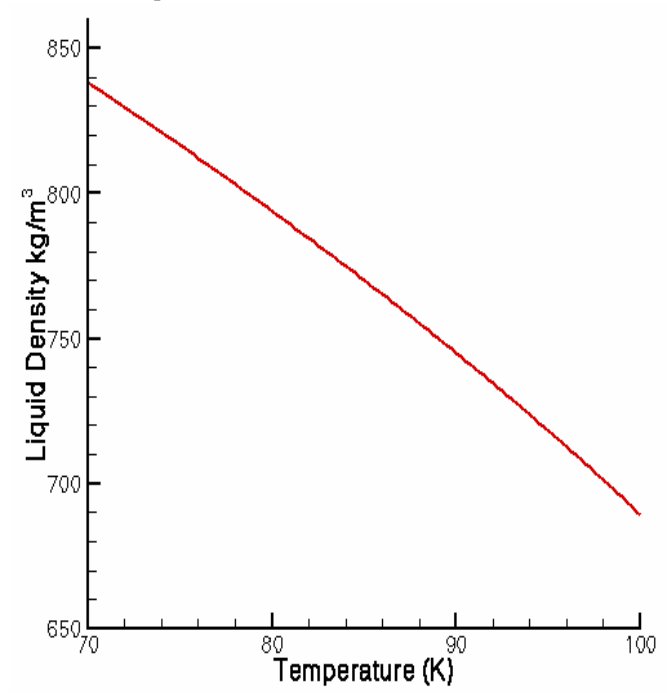

Liquid Nitrogen Density

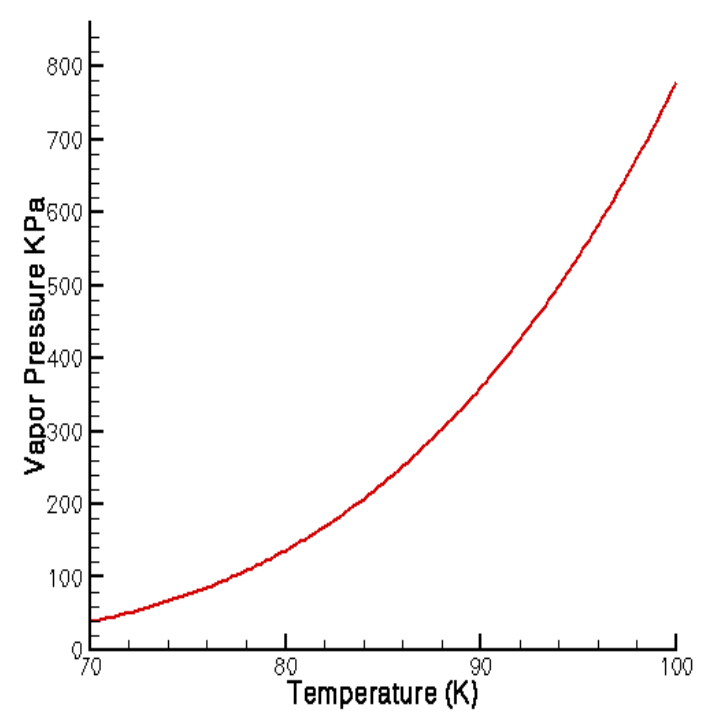

Vapor Pressure 


\section{Gas-Liquid EOS Routines}

- For Regimes that include Supercritical Flow along with Sub-critical States Specialized EOS Routines need to be used

- Close to Critical Point Vapor Phase Exhibits Non-Ideal behavior

- Property Derivatives Exhibit non-linearities and discontinuous slopes near critical Point

- Several Generalized EOS Routines that Span Supercritical/Subcritical Regimes Implemented
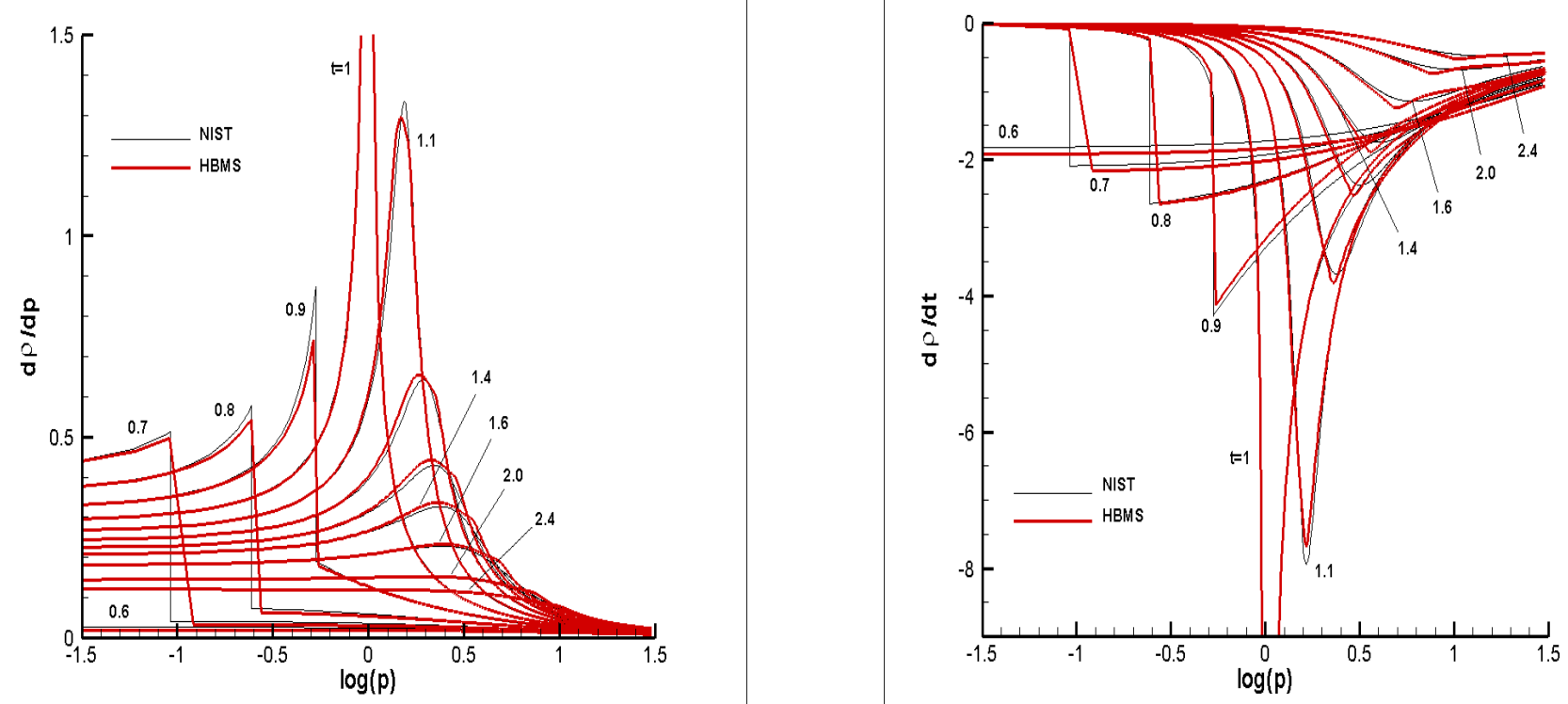


\section{HBMS Model For Real Fluids}

\section{- HBMS Model Developed by Hirschfelder, Beuler, McGee and Sutton}

- Hirschfelder, J. O., Buehler, R. J., McGee, H. A., and Sutton, J. R., "Generalized Equation of State for Gases and Liquids", Industrial and Engineering Chemistry, 50, \#3, p375, 1958.

- Hirschfelder, J. O., Buehler, R. J., McGee, H. A., and Sutton, J. R., "Generalized Thermodynamic Excess Functions for Gases and Liquids", Industrial and Engineering Chemistry, 50, \#3, p386, 1958.

- Hirschfelder, J. O., Buehler, R. J., McGee, H. A., and Sutton, J. R., "Correction and Correspondence", Industrial and Engineering Chemistry: Fundamentals, 1 p 224, 1962.

- Three Region Correlation of Real Fluid Properties based on Principle of Corresponding States

- Region I

- Density $<1$

- Region II

- Temp $>1$ Density $>1$

- Region III

- Temp $<1$ Density $>1$

- All thermodynamic properties and derivatives expressed as functions of density and temperature

- Implementation in $\mathrm{CRUNCH}$ requires a density decode at local pressure and temperature

- Evaluate density based on pressure and temperature using a Newton Iteration

- Function has multiple zeroes, iteration sensitive to initial guess

- Regions I and II density initialized by ideal gas law, Region III by liquid density, and Region IV by 0 .
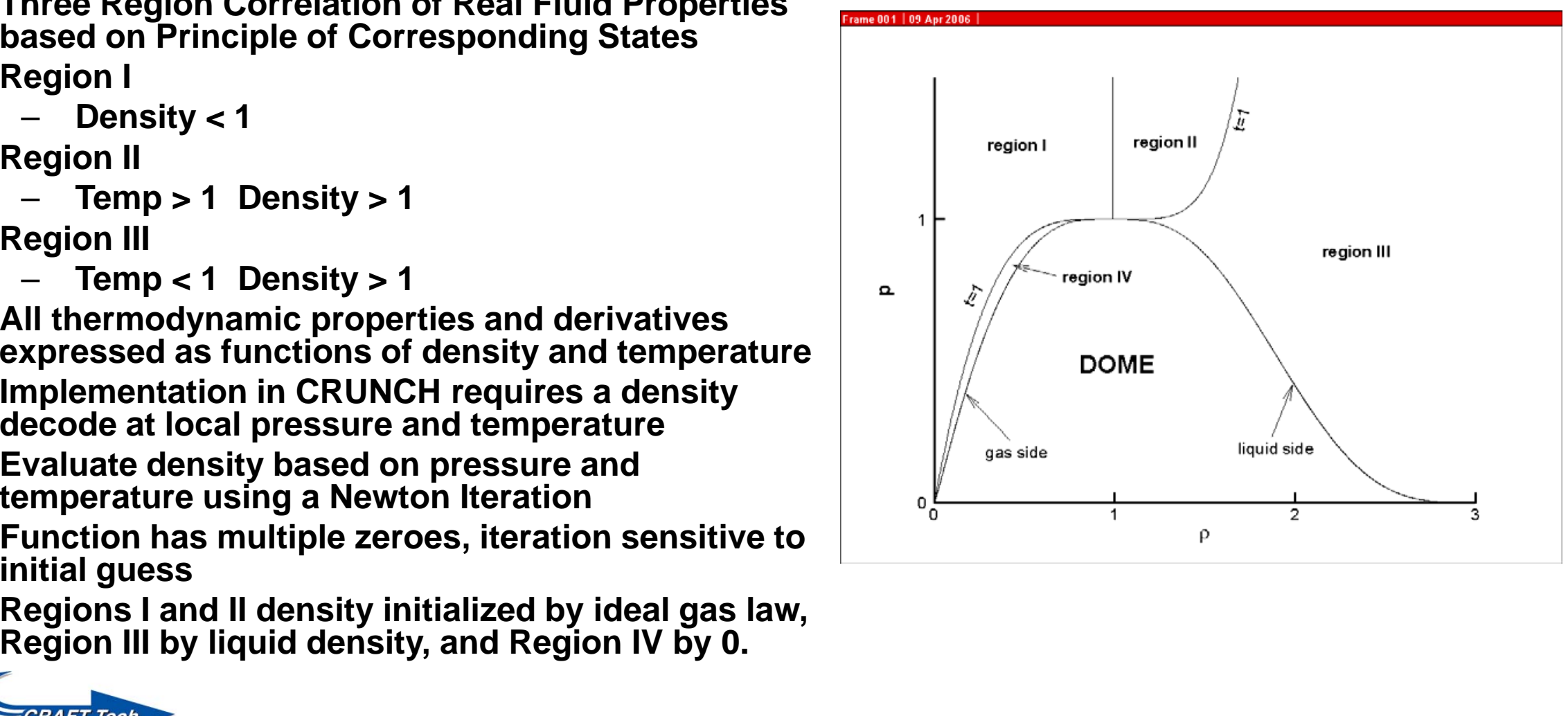


\section{HBMS Model for Real Fluids (cont.)}

- HBMS shows good comparisons with NIST for oxygen and nitrogen

- Derivatives show discontinuous slopes near the critical pt

- Questions arise about numerical stability in a CFD Framework

- In the sub-critical regime comparisons are particularly good. However, comparisons deteriorate in the supercritical region
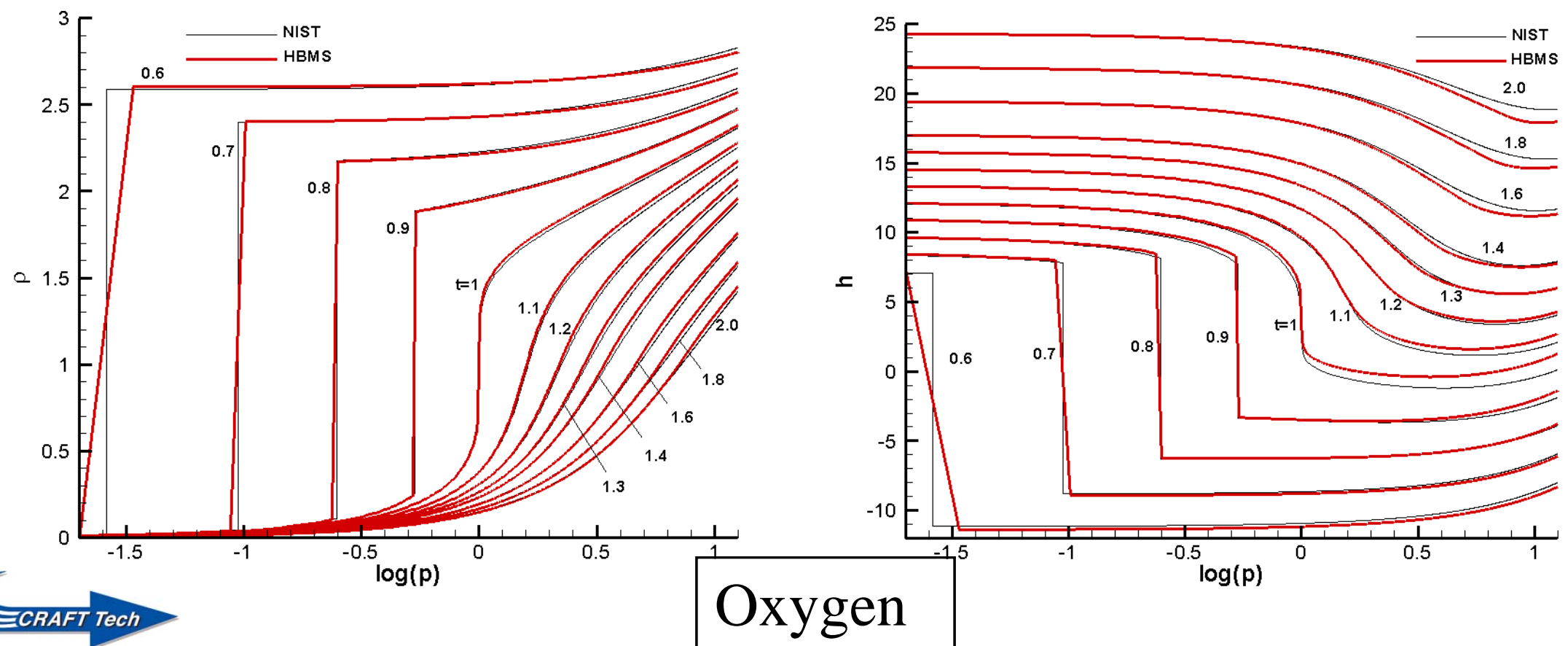


\section{Cubic EOS for Real Fluids}

- Routines based on SRK (Soave, Redlich and Kwong) and PR (Peng, Robinson) equations of state

- Routines developed by Joe Oefelein at Sandia

- Belong to a general class of "cubic equations of state"

- Unlike HBMS, Sandia EOS routines are prescribed as functions of pressure and temperature and can be directly used in a density based CFD code such as CRUNCH CFD

- Comparisons with NIST indicate correct Trends but Saturation Line Shifted - Properties on either side of dome well predicted

$$
P=\frac{R T}{V-b}-\frac{a}{V^{2}+u b V+w b^{2}}
$$

where $\mathrm{R}$ is the universal gas constant, $\mathrm{V}$ is molar volume $\mathrm{u}$ and $\mathrm{w}$ are model constants depending on PR or SRK and $a$ and $b$ are constants for a given substance which maybe a mixture in which case they are dependent on mixture composition

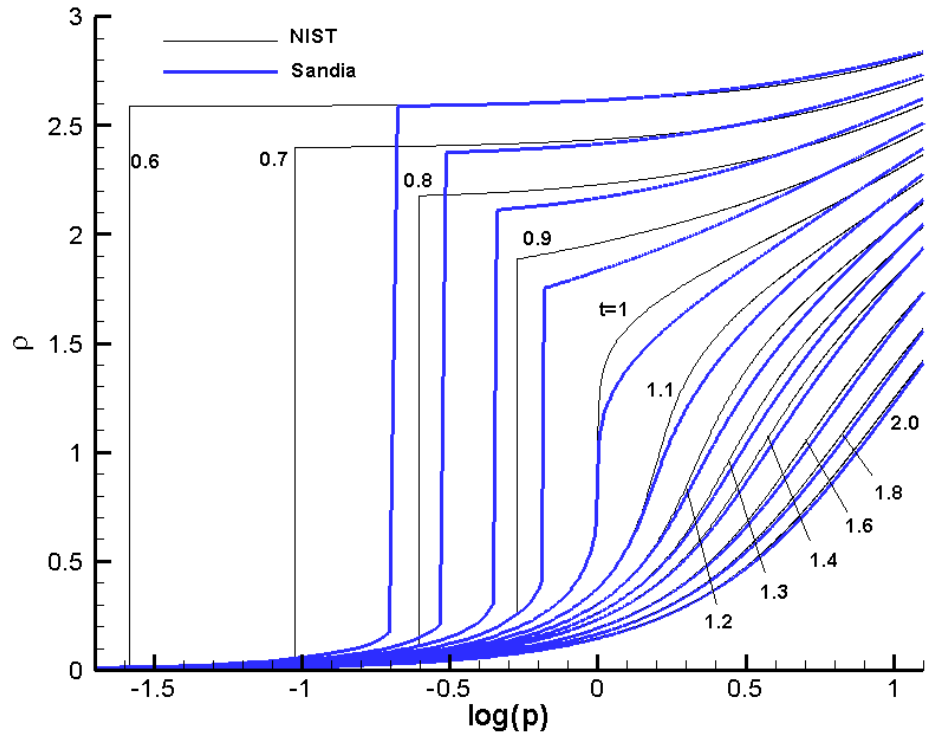




\section{Correction to Cubic EOS (SRK)}

- Since SRKIPR EOS use a cubic EOS choice of vapor pressure in these models is an approximation

- Consequently the saturation line is shifted giving rise to erroneous properties near the saturation line

- Vapor Pressure can be directly computed using Reidel's formula

- Part of the cubic replaced by the saturation line

- Determination can be made based on the local pressure and the vapor pressure whether to extract liquid or vapor properties

$p_{v}=\exp \left\{\alpha \ln (t)-0.0838(\alpha-3.75)\left[\frac{36}{t}-35-t^{6}+42 \ln (t)\right]\right\}$

where $\mathrm{pv}=\mathrm{Pv} / \mathrm{Pc}$ and $\mathrm{t}=\mathrm{T} / \mathrm{Tc}$, in which $\mathrm{Pc}$ is the critical pressures and $\mathrm{a}=\mathrm{dpv} / \mathrm{dt}$ at $\mathrm{t}=1$

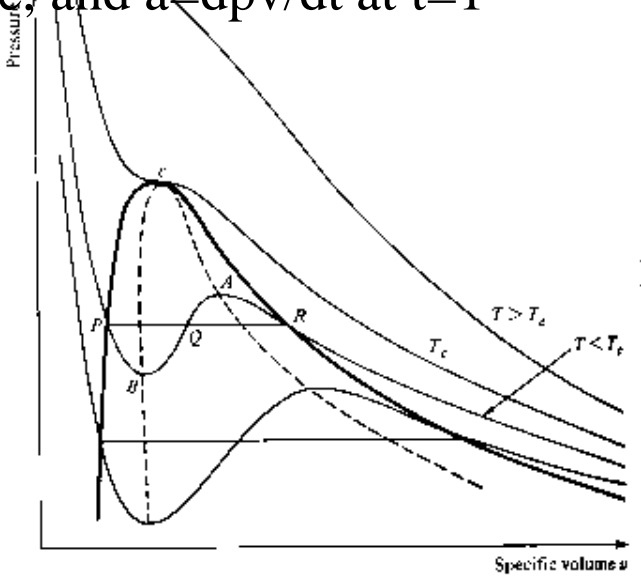

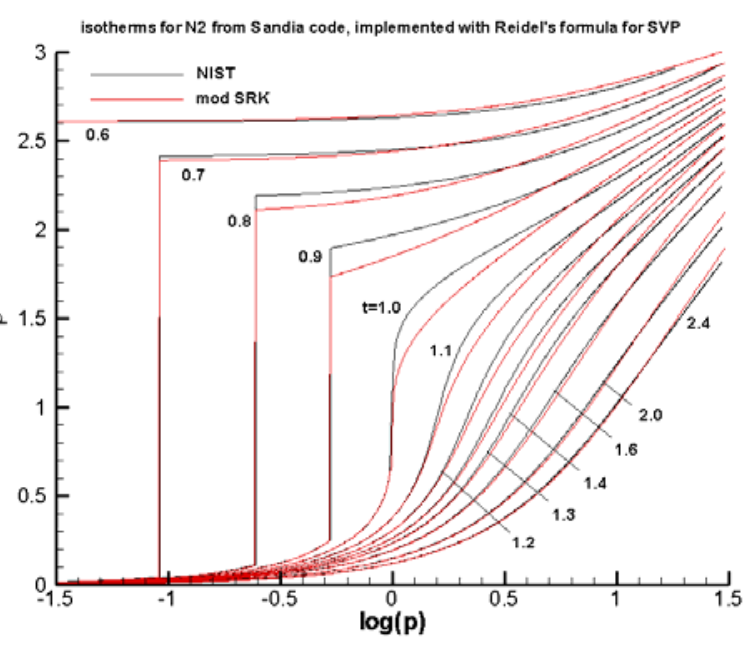

Isotherms after Correction 


\section{Thermophysical Properties}

- Thermophysical property models implemented in CRUNCH CFD for properties such as viscosity and thermal conductivity spanning different sub-critical/supercritical regimes

- Sandia model has its own routines for viscosity and thermal conductivity

- Lemmon Jacobsen model implemented for nitrogen and oxygen

- E.W. Lemmon and R.T. Jacobsen, International Journal of Thermophysics, Vol. 25, No.1, Jan. 2004, p.21-69

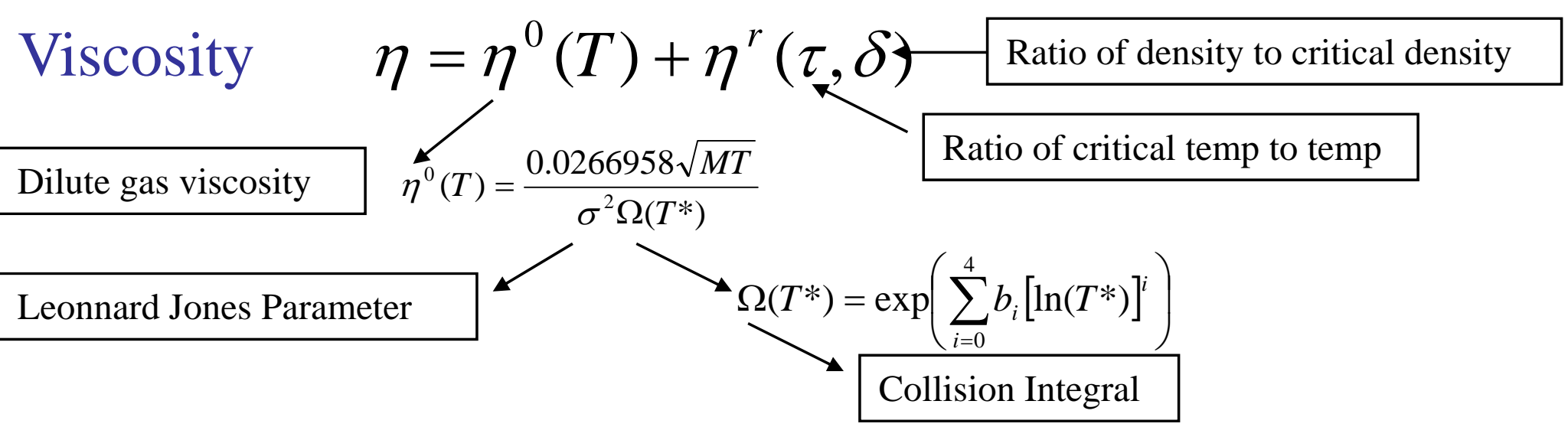




\section{Thermophysical Properties (Cont.)}
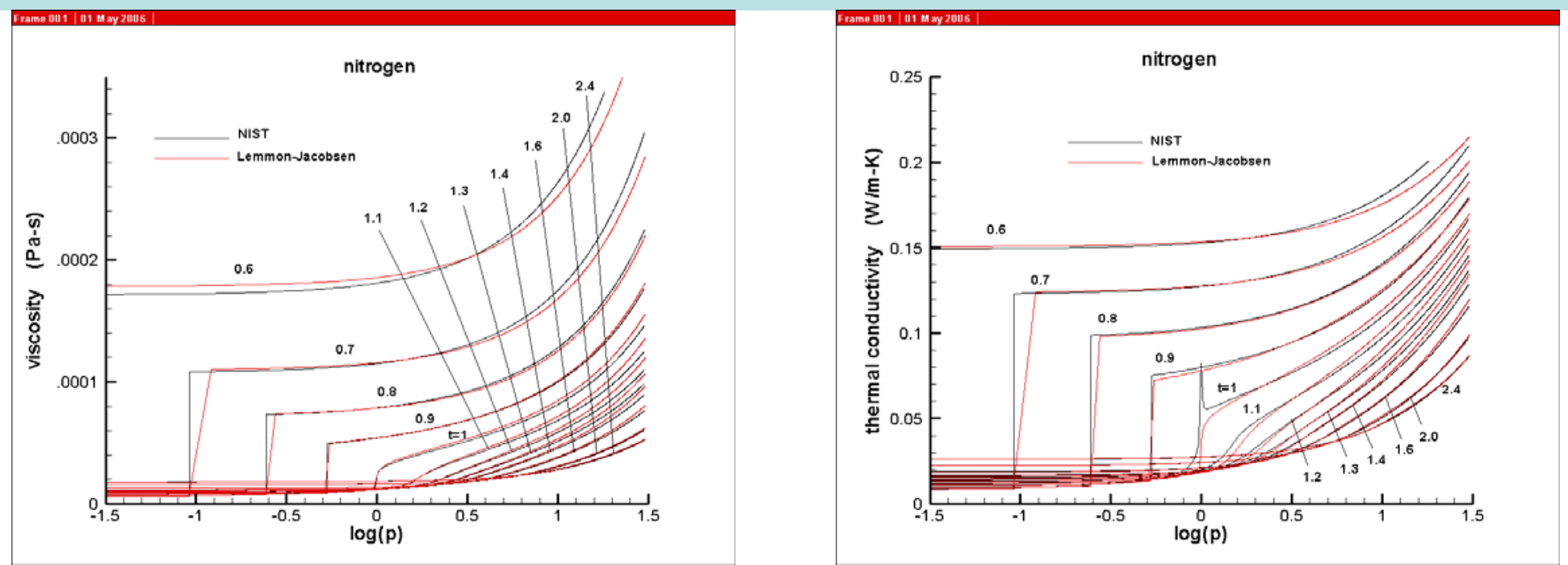

Lemmon Jacobsen Model for nitrogen
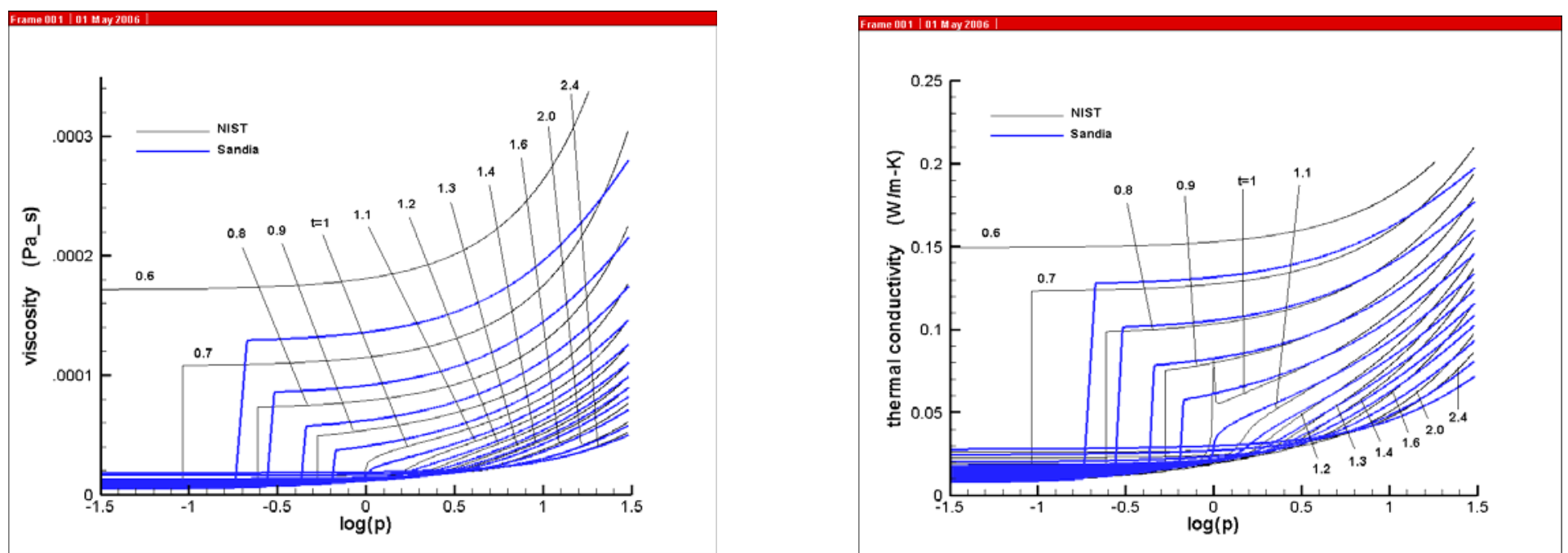

Sandia Model for nitrogen 


\section{EOS Framework for Mixture Routines}

\section{- A mixture model for property routines where multiple} fluids could exist in different states

- Eg. Gas, liquid, supercritical

- Two issues make this complicated

- Ambiguity of definition of critical point or critical surface

- In supercritical regimes mixing rules cannot be represented by simple linear combinations of mass fractions of constituents

- Tank problems such as the pressurization problem is unique because of the existence of multiple states i.e. subcritical gas, liquid, supercritical of the ullage and the propellant

- Two approaches taken to development of a mixture model

- Defining a mixture based on combination of properties of constituent components (Amagat's Law)

- Defining a cubic equation such as PR/SRK based on a composite fluid

$$
P=\frac{R_{u} T}{V-b}-\frac{a}{V^{2}+u b V+w b^{2}} \quad a=\sum_{i=1}^{n} \sum_{j=1}^{n} x_{i} x_{j} a_{i}{ }^{1 / 2} a_{j}{ }^{1 / 2} \quad b=\sum_{i=1}^{n} x_{i} b_{i}
$$




\section{EOS Framework for Mixture Routines(cont.)}

Comparisons of mixture formulation and composite fluid formulation in determining properties for mixture oxygen and nitrogen for which NIST data is available -Comparisons are made for temperatures ranging from $120 \mathrm{~K}$ to $300 \mathrm{~K}$ through critical point of Oxygen (155 K)

-Both approaches similar in supercritical regime

- Near Critical Point of Oxygen both approaches show significant deviation

-Composite Fluids Approach Closer to NIST Data

-Composite Fluids Approach shows Smooth Variation near Critical Point
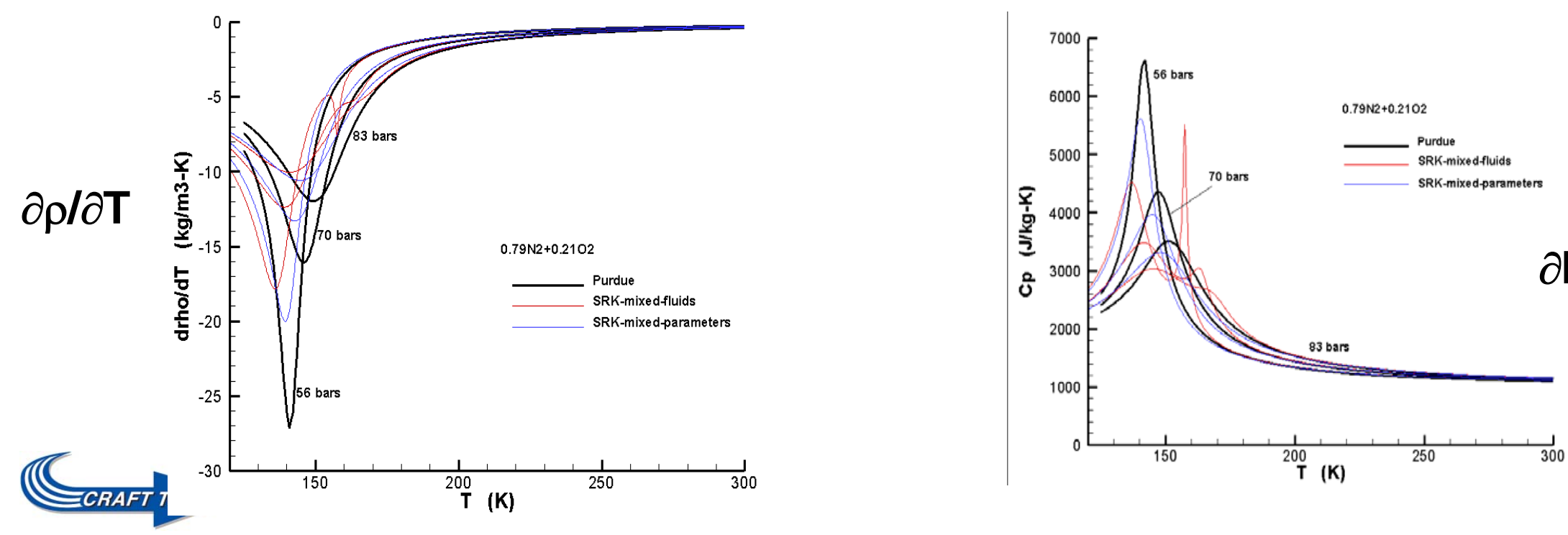


\section{VALIDATION FOR TANK SLOSHING - MSFC DROP TANK EXPERIMENT}

LRUIVLH LFU simulation

Time $=0.0080$

Time $=0.0080$
- Sloshing in a drop tank experiment at NASA MSFC simulated; liquid simulant; petroleum ether, vapor simulant: air

- Multi-Phase Simulation Performed with gas-liquid interface being resolved as part of the solution

- No Additional Interface tracking or interface fitting technique or grid adaptation used in this case

- Initial liquid surface displaced to provide source for sloshing

\section{Physical Properties: Petroleum Ether}

- Density $=618 \mathrm{~kg} / \mathrm{m} 3$

- Surface Tension=0.0149 N/m (neglected)

- Viscosity $=0.0002488 \mathrm{~kg} / \mathrm{m}-\mathrm{s}$

Gravity Acceleration Profile:

$\begin{array}{lc}-9.8 \mathrm{~m} / \mathrm{s} 2 & 0.0<\mathrm{t}<0.08 \mathrm{~s} \\ -1.75 \mathrm{~m} / \mathrm{s} 2 & 0.08 \mathrm{~s}<\mathrm{t}<0.09 \mathrm{~s} \\ -1.06 \mathrm{~m} / \mathrm{s} 2 & 0.09 \mathrm{~s}<\mathrm{t}<0.10 \mathrm{~s} \\ -0.89 \mathrm{~m} / \mathrm{s} 2 & 0.10 \mathrm{~s}<\mathrm{t}<0.20 \mathrm{~s} \\ -0.51 \mathrm{~m} / \mathrm{s} 2 & 0.20 \mathrm{~s}<\mathrm{t}<0.30 \mathrm{~s} \\ -0.21 \mathrm{~m} / \mathrm{s} 2 & 0.30 \mathrm{~s}<\mathrm{t}<0.356 \mathrm{~s} \\ -0.10 \mathrm{~m} / \mathrm{s} 2 & 0.356 \mathrm{~s}<\mathrm{t}<4.0 \mathrm{~s}\end{array}$$$
0.08 \mathrm{~s}<\mathrm{t}<0.09 \mathrm{~s}
$$$$
0.09 \mathrm{~s}<\mathrm{t}<0.10 \mathrm{~s}
$$$$
0.10 \mathrm{~s}<\mathrm{t}<0.20 \mathrm{~s}
$$$$
0.20 \mathrm{~s}<\mathrm{t}<0.30 \mathrm{~s}
$$$$
0.356 \mathrm{~s}<\mathrm{t}<4.0 \mathrm{~s}
$$ 


\section{Comparison of Experiment and Computational}

Flowfield with Gas-Liquid Iso-Surface

Experiment
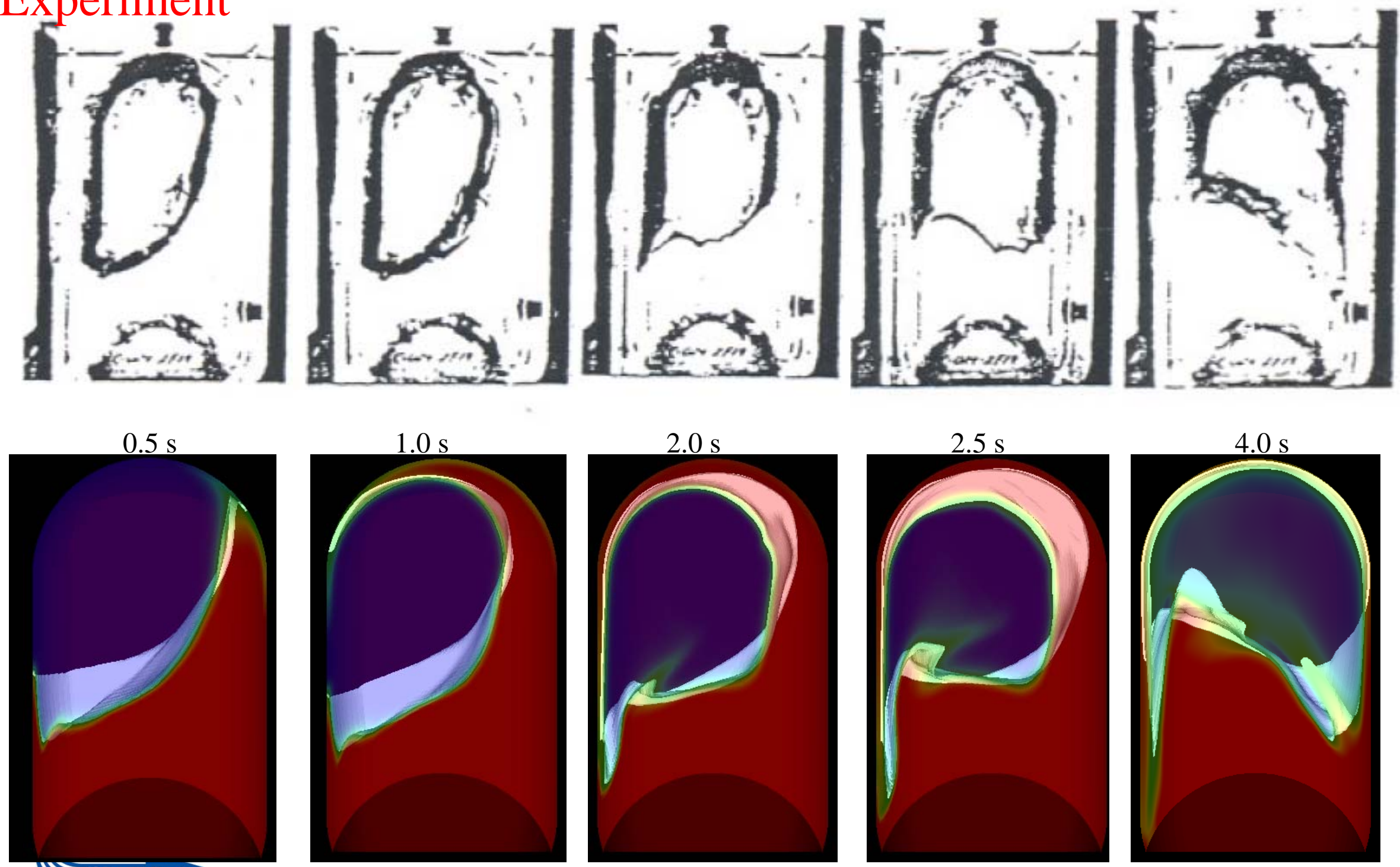

WCRAFT Tech

$\overline{\text { Fine Grid }-} \overline{\text { Fully Viscous Simulation }}$ 


\section{VALIDATION FOR PHASE CHANGE - AS-203 SELF- PRESSURIZATION EXPERIMENT}

- Simulations of Saturn AS-203 SelfPressurization Fuel Tank Experiment

- Fuel Tank Modeled with its Slosh Deflector and Baffle

- Tank was instrumented for pressure and temperature measurements during orbiting SIV-B stage

- Variable Heat Flux Distribution on various segments of Tank

- Tank contained $16,000 \mathrm{lbm}$ of liquid Hydrogen and had an initial pressure of 12.4 psia

\section{Liquid Hydrogen}

Fuel Tank in AS-203

Self-Pressurization

Experiment

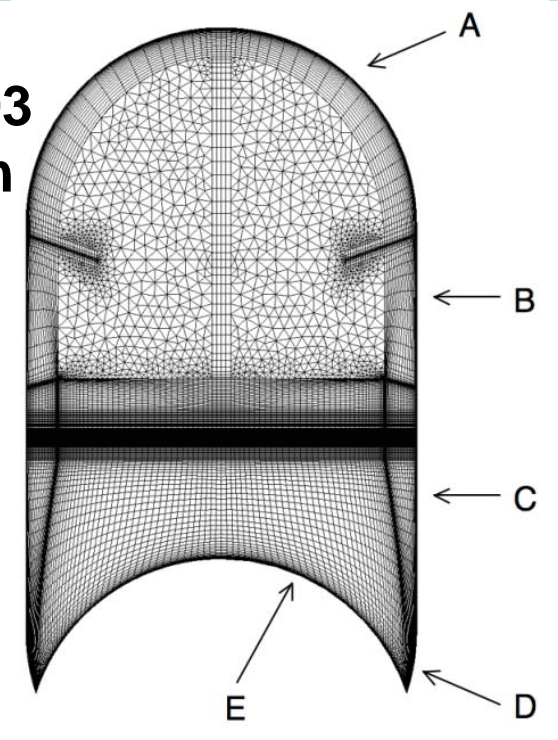

Heat Flux Distribution

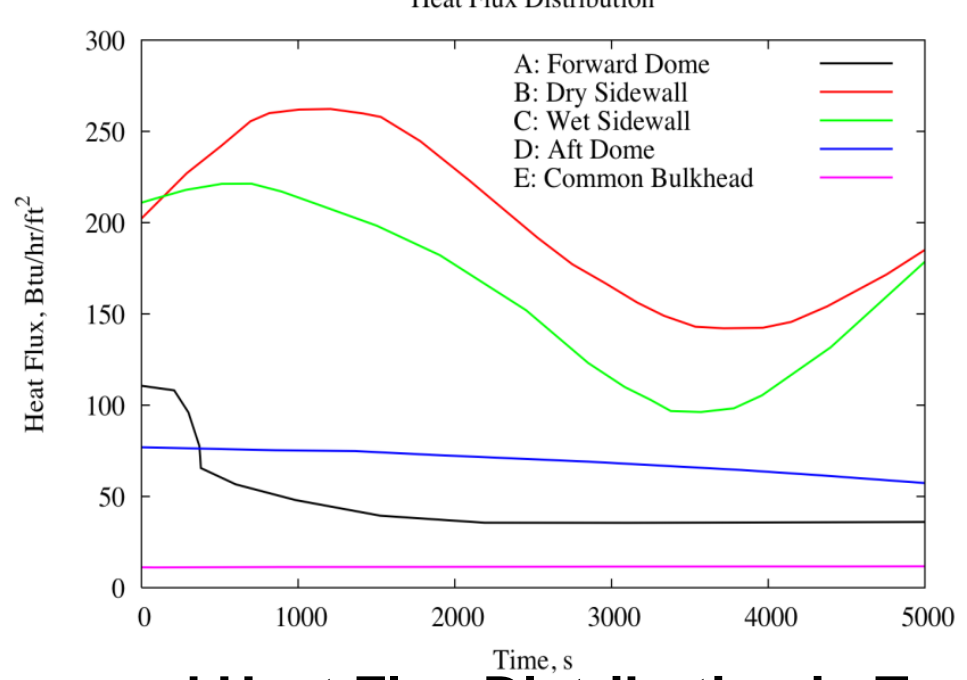

Measured Heat Flux Distribution in Tank 


\section{COMPARISONS OF CFD PREDICTIONS and}

\section{EXPERIMENTAL MEASUREMENTS/DEDUCTIONS}

- During Experiment conditions recorded during first 600 secs before Telemetry Blackout

- Increase in Pressure combination of heat transfer from walls and propellant boil-off

- Development of Thermal Boundary Layers and convective cells in Tank

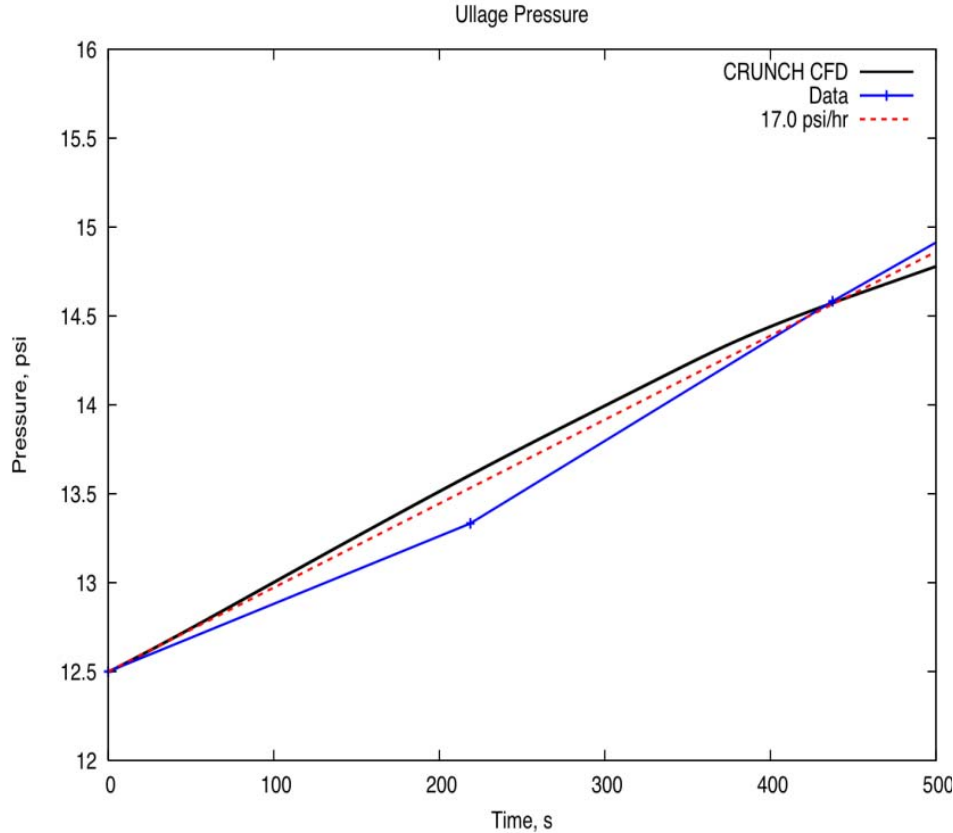

Predicted and Measured Ullage Pressure Rise during Self-Pressurization

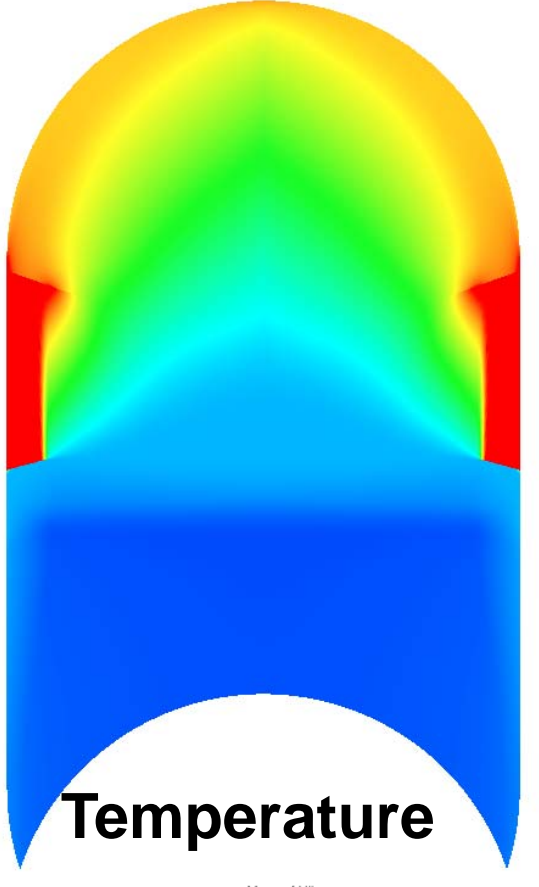

$\mathrm{T}[\mathrm{R}]$
45.0
42.5
40.0
37.5
35.0

Mass of Ullag

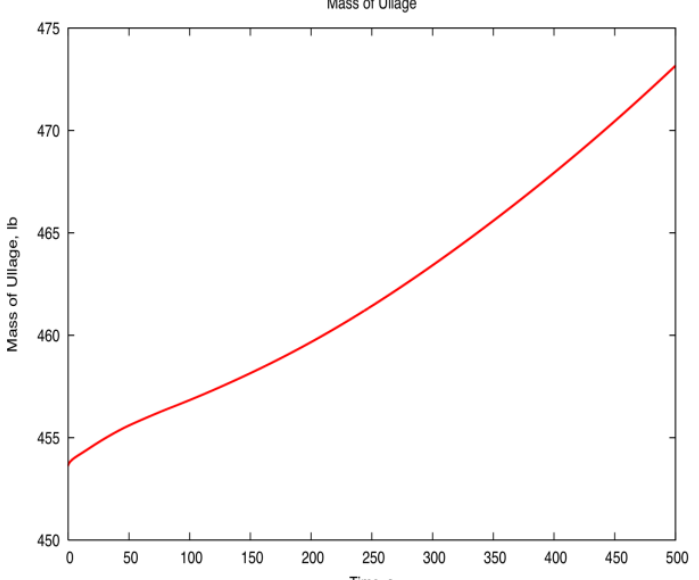

Predicted Mass Increase in Ullage 


\section{PRESSURIZATION OF LOX TANK}

- Simulations of High Pressure Lox System in E-1 Test Complex at NASA SSC

- System Comprises of 2600 Gallon LOX Dewar Run Tank

- High Pressure Source of Pressurant Gas(Nitrogen) substituted for Oxygen in Simulation

- Constant Mass Flow of Gas injected into Tank at $1158 \mathrm{lbm} / \mathrm{s}$

- Flow Enters Tank Radially through Diffuser

- Individual Holes of Diffuser not modeled

- Simulation Started at Pre-pressurization conditions

- $90 \%$ liquid $10 \%$ ullage

- Ullage at 325 psia, $135.16 \mathrm{~K}$

- Liquid Sub-cooled at $90.18 \mathrm{~K}$

- System Encompasses entire spectrum from compressed liquid, supercritical to superheated compressible

- System pressurizes from 325 psia to 1350 psia in 0.3 secs. 


\section{PRESSURIZATION OF LOX TANK}

Temperature Distribution
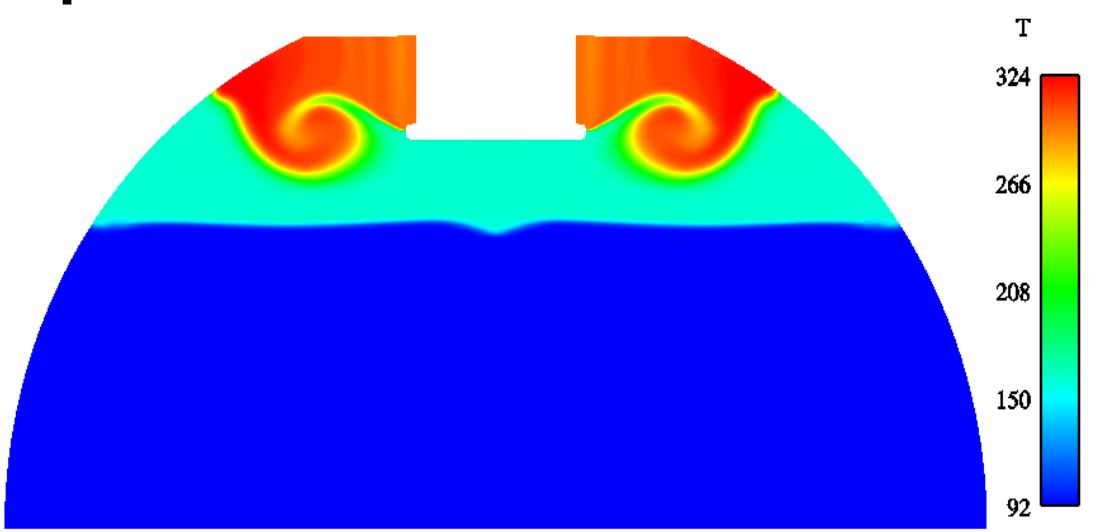

$$
\mathrm{T}=\mathbf{0 . 0 5} \mathrm{secs}
$$

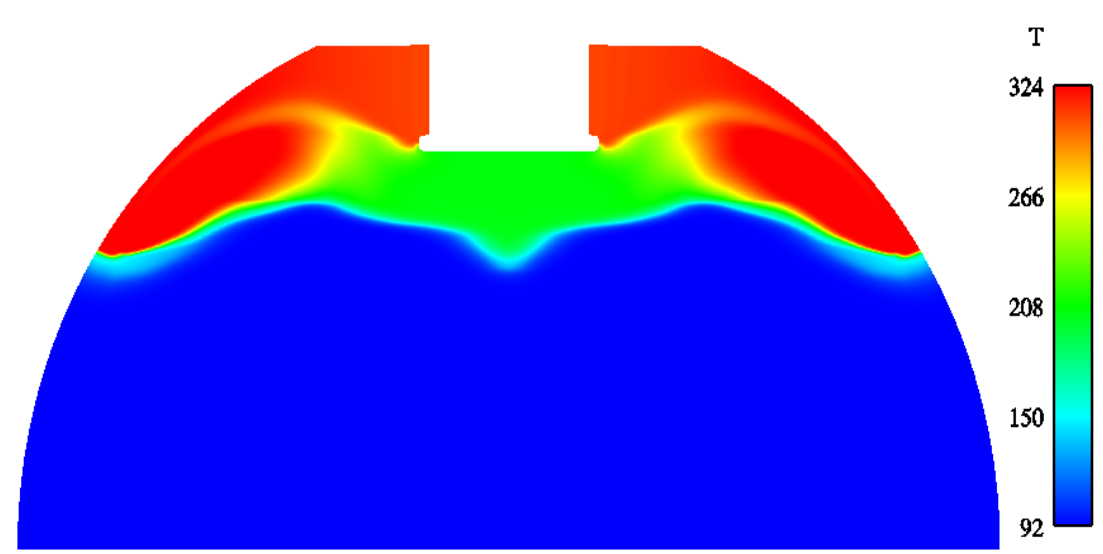

$$
\mathrm{T}=0.2 \operatorname{secs}
$$

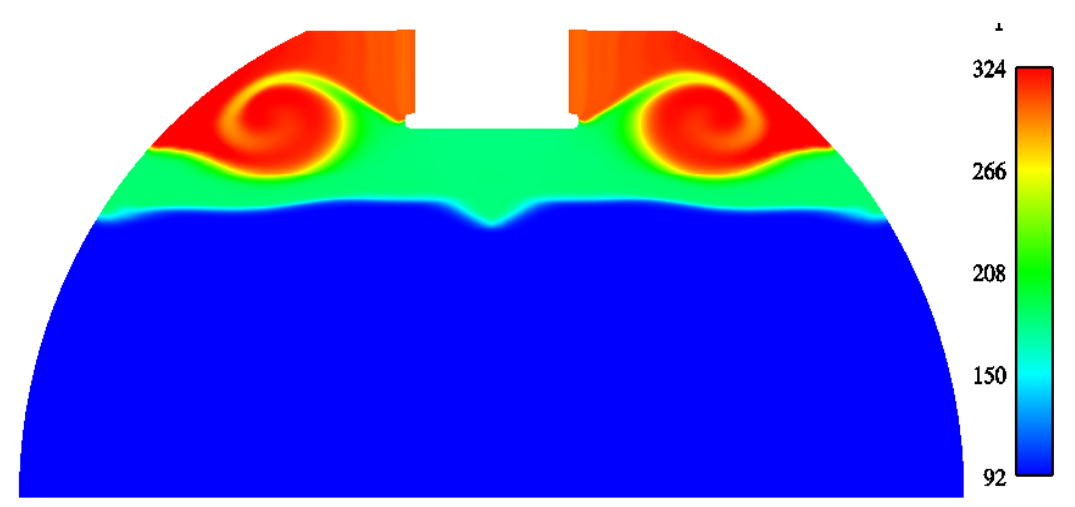

$$
\mathrm{T}=0.1 \mathrm{secs}
$$

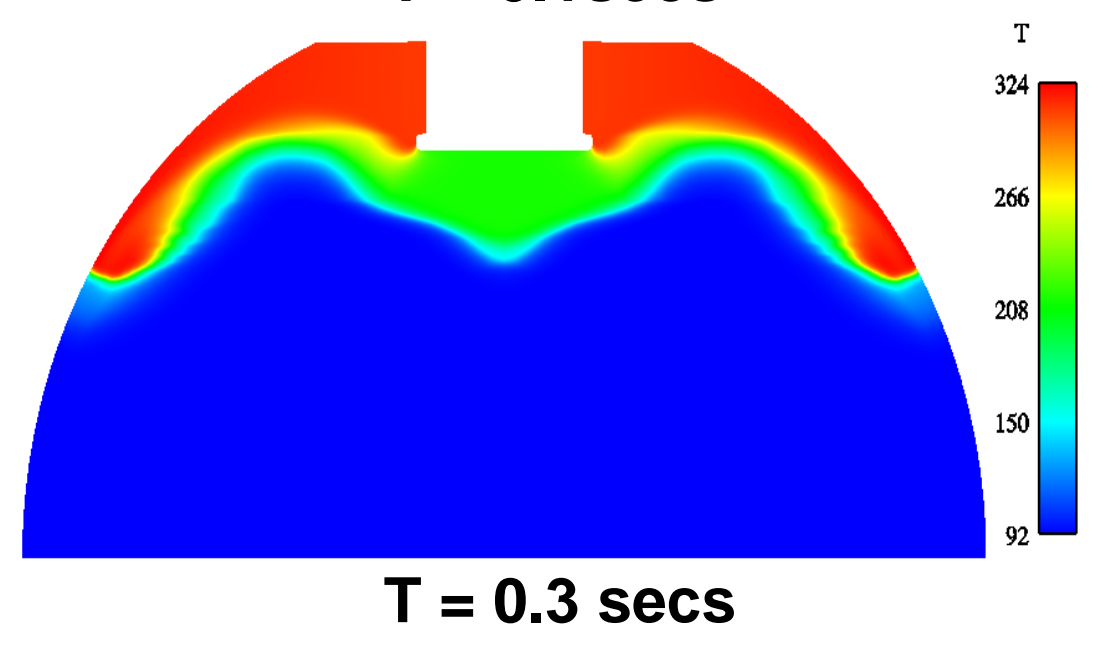




\section{PRESSURIZATION OF LOX TANK (cont)}

\section{Density Distribution}
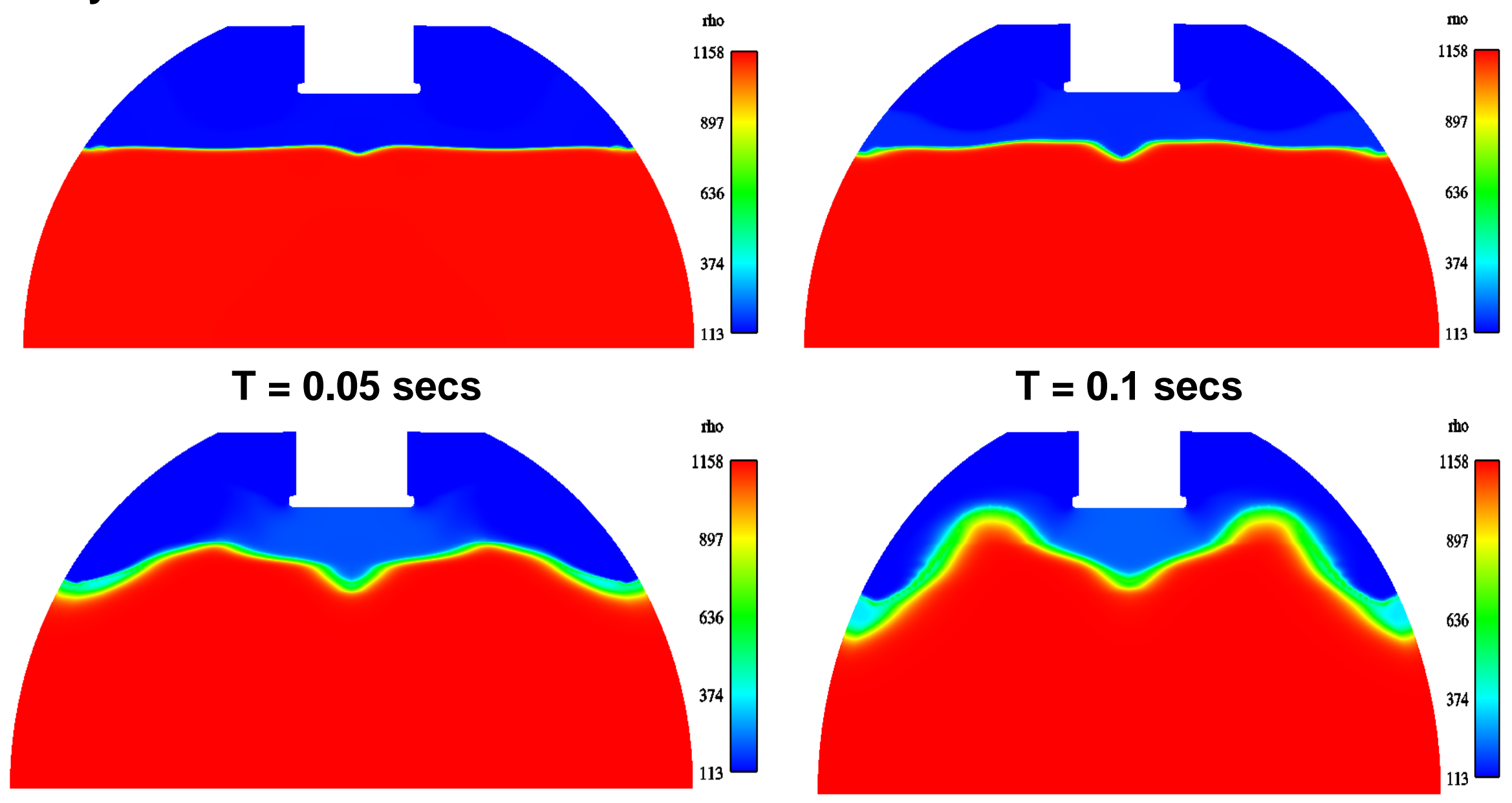

$T=0.2$ secs

$$
\mathrm{T}=0.3 \mathrm{secs}
$$

$\mathbb{G}_{\text {CRAFT Tech }}$ 


\section{Propellant Drain Tank Modeling}

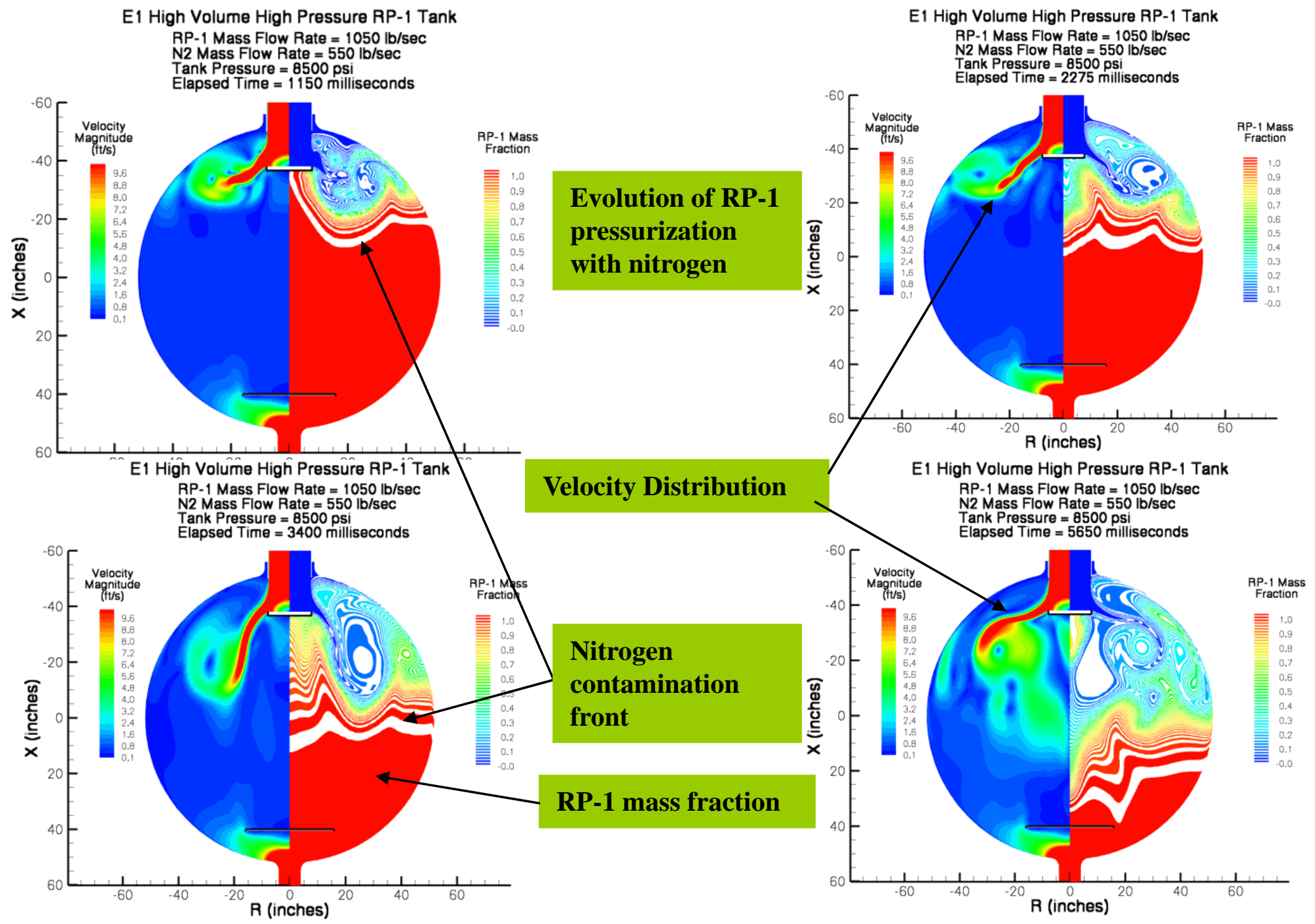




\section{SUMMARY}

- Advanced Gas/Liquid Framework with Real Fluids Property Routines

- A multi-fluid formulation in the preconditioned CRUNCH CFD ${ }^{\circledR}$ code developed where a mixture of liquid and gases can be specified

- Various options for Equation of state specification available ( from simplified ideal fluid mixtures, to real fluid EOS such as SRK or BWR models)

- Vaporization of liquids driven by pressure value relative to vapor pressure and combustion of vapors allowed

- Extensive validation has been undertaken

- Currently working on developing primary break-up models and surface tension effects for more rigorous phase-change modeling and interfacial dynamics

- Framework Applied to Run-time Tanks at Ground Test Facilities

- Framework Used For J-2 Upper Stage Tank Modeling

- NASA MSFC tank pressurization

- Hydrogen and oxygen tank pre-press, repress and draining being modeled at NASA MSFC.

- NASA AMES tank safety effort

- liquid hydrogen and oxygen are separated by a baffle in the J-2 tank. We are modeling pressure rise and possible combustion if a hole develops in the baffle and liquid hydrogen leaks into the oxygen tank. Tank pressure rise rates simulated and risk of combustion 